\title{
Description of the female of Poeciloxestia plagiata (Waterhouse, 1880), and of the male of luati spinithorax Martins \& Galileo, 2010 (Coleoptera, Cerambycidae)
}

\author{
Francisco Eriberto de Lima Nascimento ${ }^{1,2}$, Antonio Santos-Silva ${ }^{1,3}$ \& Juan José Ramírez Hernández ${ }^{4}$ \\ 1 Universidade de São Paulo (USP), Museu de Zoologia (MZUSP). São Paulo, SP, Brasil. \\ ${ }^{2}$ ORCID: 0000-0002-5047-8921. E-mail: eribnascimentofl@gmail.com \\ 3 ORCID: 0000-0001-7128-1418. E-mail: toncriss@uol.com.br \\ ${ }^{4}$ Iquitos, Loreto, Peru. E-mail: macrodontia@hotmail.com
}

\begin{abstract}
Based on material recently collected in Peru (Loreto department) the female of Poeciloxestia plagiata (Waterhouse, 1880), and the male of luati spinithorax Martins \& Galileo, 2010 are described and figured for the first time. Both species are recorded for the first time from Peru.
\end{abstract}

Key-Words. Cerambycinae; Cerambycini; Sphallotrichina; South America; Taxonomy.

\section{INTRODUCTION}

Poeciloxestia Lane, 1965, currently includes 20 species distributed from Mexico to southern South America (Monné, 2018). Only three species are known from Peru: $P$. hirsutiventris Fragoso, 1978; P. melzeri Lane, 1965; and P. lateralis (Erichson, 1847).

luati is monotypic and was described by Martins \& Galileo (2010) for their new species I. spinithorax from Brazil, based only on female.

The specimens studied here were collected by the third author, who conducted extensive surveys in the department of Loreto (Peru), and found them among very interesting specimens of longhorned beetles. As a result, in this work, we describe for the first time the female of Poeciloxestia plagiata (Waterhouse, 1880) and the male of luati spinithorax, both of them known only by their holotype specimens. Additionally, both species are newly recorded for Peru. The discovery of those specimens allow us to update the key for Poeciloxestia plagiata and improve the original description of the genus /uati.

\section{MATERIAL AND METHODS}

Photographs were taken with a Canon EOS Rebel T3i DSLR camera, Canon MP-E $65 \mathrm{~mm}$ f/2.8 1-5X macro lens, controlled by Zerene Stacker AutoMontage software. Measurements were taken in "mm" using measuring ocular Hensoldt/
Wetzlar - Mess 10 in the Leica MZ6 stereomicroscope, also used in the study of the specimens.

The collection acronyms used in this study are as follows:

JJRH - Juan José Ramírez Hernandez private collection, Loreto, lquitos, Peru.

MZSP - Museu de Zoologia, Universidade de São Paulo, São Paulo, Brazil.

\section{RESULTS}

\section{Poeciloxestia plagiata (Waterhouse, 1880)}

(Figs. 1-6)

Description: Female: Integument mostly black; mouthparts dark brown except dark reddish brown apex of palpomeres; antennae dark brown from antennomere VII; each elytron with two large orange maculae: one oblique, irregular, placed on basal half, not reaching lateral margin norsuture; another elongate, placed on sides of posterior half, not reaching lateral margin, almost reaching apex.

Head: Frontal plate not well-delimited; frontolateral depressions moderately deep; frontolateral ridges distinct, moderately elevated; entire frontal surface coarsely, confluently punctate except narrowed longitudinal smooth area, slightly elevated, in which the median groove is inserted; punctures with minute whitish setae. Vertex 

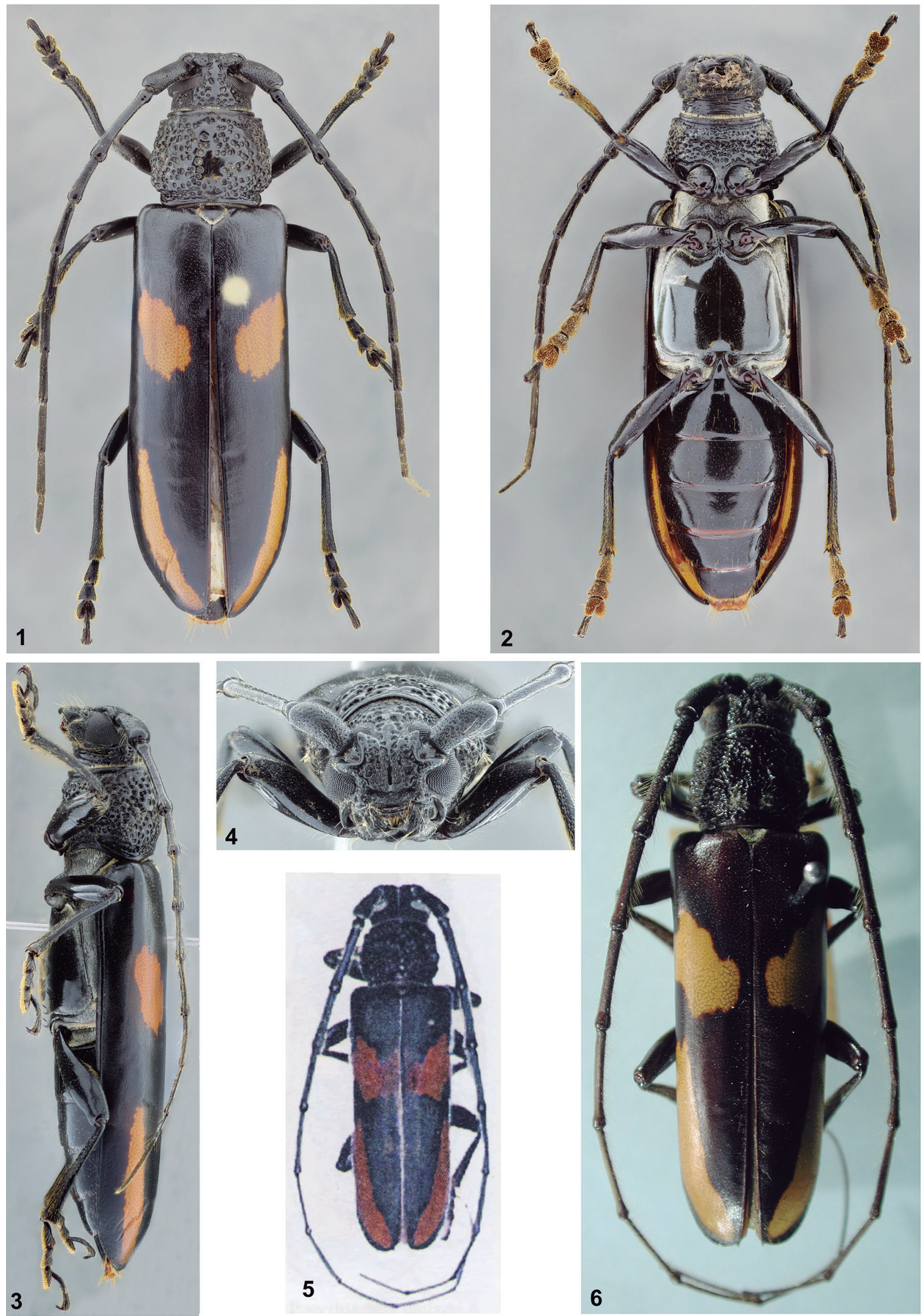

Figures 1-6. Poeciloxestiaplagiata: (1) Dorsal habitus, female; (2) Ventral habitus, female; (3) Lateral habitus, female; (4) Head, frontal view, female; (5) Holotype male, dorsal habitus, photo by Jesus Santiago Moure; (6) Holotype male, from Larry Bezark photograph collection. 
coarsely, abundantly punctate between antennal tubercles and area between upper eye lobes (punctures as on frons between antennal tubercles, coarser on remaining surface), except smooth, longitudinal central area, slightly finer, more abundant close to prothoracic margin; nearly all punctures with minute whitish setae. Area behind central area of upper eye lobes coarsely, confluently punctate (punctures as on area of vertex close to prothoracic margin); superior area with sculpturing as on vertex; inferior area smooth on nearly triangular area close to eye (this area reaching superior area of lower eye lobe), coarsely, slightly sparsely punctate close to prothorax; nearly all punctures with minute whitish setae. Area behind lower eye lobes coarsely, moderately shallowly and abundantly punctate on tumid area close to eye, coarsely striate-punctate close to prothorax, deeply longitudinally sulcate between these areas; part of punctures on tumid area with minute whitish setae, and area between punctures with sparse, long, erect yellowish-white setae on inferior half. Antennal tubercles coarsely, shallowly punctate (punctures finer than on frons), except finely punctate apical area; punctures with minute whitish setae. Median groove distinct from near clypeus to area between antennal tubercles. Postclypeus coarsely, shallowly, confluently punctate on wide central area, except moderately deeply, well-delimited punctures close to smooth lateral sides; with minute, very sparse whitish setae on punctate area, long, erect golden setae on sides of wide central area, and moderately short, sparse yellowish-white setae on sides of inclined area close to anteclypeus. Labrum coplanar with anteclypeus on posterior half, distinctly inclined, depressed on anterior half; posterior half finely, sparsely punctate, with minute, sparse whitish setae centrally, and long, erect, moderately abundant golden setae laterally; depressed area of anterior half with long, erect, dense golden setae. Genae coarsely, partially shallowly punctate; with short, decumbent, sparse yellowish-white setae; with a few long, erect golden setae. Gulamentum glabrous, coarsely, transversely striate on posterior half; depressed on anterior half, coarsely, shallowly, confluently punctate, with short, moderately sparse yellowish-white setae interspersed with long, erect setae of same color. Distance between upper eye lobes 0.47 times length of scape; in frontal view, distance between lower eye lobes 0.85 times length of scape. Antennae 1.27 times elytral length, reaching posterior $1 / 10$ of elytra. Scape nearly parallel-sided; finely, abundantly punctate dorsally and laterally, rugose ventrally; with minute whitish setae emerging from nearly all punctures; with a few moderately short, erect yellowish setae dorsally, a few long, erect setae laterally, and both short and long, erect yellowish setae ventrally, slightly more abundant on posterior half. Pedicel very finely, sparsely punctate; with minute whitish setae emerging from punctures dorsally and laterally, and long, erect, sparse yellowish setae ventrally. Antennomere III finely, moderately sparsely punctate except smooth distal area; with minute whitish setae emerging from nearly all punctures, and long, erect, moderately abundant yellowish setae ventrally, sparser dorsally. Antennomeres IV-X with fine punctures, gradually denser toward $X$ (becoming densely micropunctate) except smooth distal area, and short yellowish-brown pubescence, gradually denser toward $X$; erect setae as on III, but shorter toward X. Antennomere XI densely micropunctate; with yellowish-brown pubescence interspersed with long, moderately short, sparse yellowish setae (sparser dorsally). Antennal formula (ratio) based on length of antennomere III: scape $=0.69$; pedicel $=0.13$; $\mathrm{IV}=0.57 ; \mathrm{V}=0.68 ; \mathrm{VI}=0.67 ; \mathrm{VII}=0.65 ; \mathrm{VIII}=0.61 ; \mathrm{IX}=0.60$; $\mathrm{X}=0.57 ; \mathrm{XI}=0.69$.

Thorax: Prothorax 1.4 times wider than long; anteriorly and posteriorly abruptly constricted, anterior constriction distinctly narrower than posterior constriction; with narrow transverse sulcus surrounding area adjacent to anterior constriction. Pronotum coarsely, abundant punctate, except smooth central area and narrow area close to anterior margin, distinctly confluent laterally (becoming strongly rugose); with minute yellowish setae emerging from some punctures on anterior half and center of posterior half, with long, erect setae emerging from some punctures on sides of posterior half. Sides of prothorax coarsely, densely, confluently punctate (becoming strongly rugose) except smooth narrow area close to anterior and posterior margins; with a few long, erect yellowish setae emerging from some punctures. Prosternum coarsely, confluently punctate between procoxal cavities and anterior constriction (becoming rugose), nearly smooth from constriction to anterior margin; with moderately narrow sulcus close to anterior margin of procoxal cavities; with short yellowish setae emerging from some punctures, and long, erect setae emerging from some other punctures. Prosternal process with sides and central area elevated; with sparse yellowish-white pubescence on sides of area between coxae, distinctly more abundant on apex. Metaventrite with sparse yellow pubescence (more whitish depending on light intensity); mesanepisternum with yellowish pubescence partially obscuring integument (more whitish depending on light intensity); mesepimeron with yellowish pubescence not obscuring integument, distinctly denser, yellower on narrow area close to metanepisternum. Metanepisternum and sides of metaventrite with yellowish pubescence nearly obscuring integument, and remaining surface of metaventrite with minute, sparse yellowish setae except glabrous central area. Scutellum minutely, densely punctate laterally, smooth centrally; with yellowish-white pubescence along lateral margins, glabrous centrally. Elytra: Somewhat opaque; very finely, abundantly punctate, with each puncture surrounded by surface finely reticulate; with minute, sparse whitish setae near humeri, and a few short, erect yellowish setae near apex; anterior 2/3 parallel-sided, and posterior third gradually narrowed toward apex; apex rounded, sutural angle very slightly projected. Legs: Femora finely, sparsely punctate, slightly finer, more abundant toward apex; with minute, sparse whitish setae dorsally and laterally, and long, erect, sparse yellowish setae on basal half of ventral side. Tibiae moderately finely and abun- 
dantly punctate; with short, sparse yellowish setae, distinctly longer, denser, yellowish-brown on distal half of lateral and ventral surface.

Abdomen: Ventrites finely, sparsely punctate; with short yellowish setae emerging from some punctures, and a few long, erect yellowish setae emerging from some other punctures, especially on distal third; apex of ventrite $\checkmark$ rounded.

Dimensions (mm), one female: Total length, 36.10; prothoracic length, 5.50; anterior prothoracic width, 5.40; posterior prothoracic width, 6.25 ; maximum prothoracic width, 7.60; humeral width, 9.15; elytral length, 25.60.

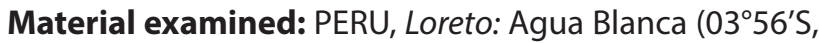
$73^{\circ} 28^{\prime}$ W), 1 female, 16.I.2011, J.J.R. Hernandez col. (JJRH). New country record.

Remarks: Poeciloxestia plagiata was described and was known only from a single male specimen from Ecuador (Gualaquiza, Morona-Santiago). The female collected in Peru agrees very well with the photograph and original description of the male.

The female of $P$. plagiata (Figs. 1-4) differs from the male (Figs. 5-6) by the antennae distinctly shorter, not reaching elytral apex, pronotal sculpturing more sparsely punctate on central area, anterior orange elytral macula not reaching lateral margin, elytra more distinctly narrowed at distal third, and sutural angle of the elytra only slightly projected. In the male, the antennae are distinctly longer than body, pronotal sculpturing denser on central area, anterior orange elytral macula reaching lateral margin, elytra less narrowed on distal third, and the sutural angle of the elytra has a short spine.

The discovery of the female of $P$. plagiata allows updating the alternative of couplet ' 9 ' from Martins \& Monné (2005) (translated):

9(8). Elytral apex unarmed in both sexes; antennae in male reaching elytral apex at about apex of the antennomere IX; anterior orange macula of the elytra fused with posterior one in both sexes. Peru, Bolivia, Brazil (Minas Gerais, Espírito Santo, Rio de Janeiro)

P. melzerilane, 1965

Elytral apex with short spine at sutural angle in male, slightly projected in female; antennae in male reaching elytral apex before apex of antennomere VII; anterior orange macula not fused with posterior one in either sex. Ecuador, Peru.

P. plagiata (Waterhouse, 1880)

Note: According to Martins \& Monné (2005), the antennae in the male of $P$. plagiata reach the elytral apex at the middle of antennomere VIII. Actually, we observed that they reach the apex before the apex of antennomere VII.

According to Martins \& Monné (2005) (translated): "FRAGOSO (1982) transferred P. plagiata from Criodion, and considered it very similar to $P$. melzeri, but with a different antennal formula. Actually, males of $P$. plagiata have elongated III-V antennomeres, while those of $P$. mel- zeri are short and robust; in P. plagiata, the antenna of the males reaches the apex of the elytra at the end of the antennomere VII and the antennae are markedly longer than in $P$. melzeri (reaching the apex of the elytra at the end of the antennomere IX);" and "FRAGOSO (1978a: 135) examined specimens from the following places: Peru, Junín: Satipo. Brazil, Espírito Santo: Condurú, Guandú, Itapemirim, Linhares, Matilde, Vagem Alta; Minas Gerais: Manhuassu; Rio de Janeiro: Rio de Janeiro (Horto Florestal, Represa Rio Grande). Bolivia, Santa Cruz: Buena Vista. The same author, in 1982, questioned whether the specimens examined from Peru and Bolivia belonged to P. plagiata or P. melzeri. In case this assumption is correct, P. melzeri occurs in the Atlantic Forest." It is probable that P. melzeri really does not occur in Peru.

\section{Iuati Martins \& Galileo, 2010}

Iuati Martins \& Galileo, 2010: 84; Monné, 2012: 12 (cat.), 2018: 96 (cat.).

Redescription (mostly translation from Martins \& Galileo, 2010): Frons transverse, elevated in relation to the ocular lobes. Frontoclypeal sulcus deep and curved. Median groove very distinct between antennal tubercles. Vertex carinate between antennal tubercles and upper eye lobes. Antennal tubercles close to each other, slightly elevated, rounded at apex. Eyes without setae between ommatidia. Lower eye lobes more distant from each other than insertion of antennae; upper eye lobes more distant from each other than width of one upper lobe. Genae with rounded apex. Antennae in female reaching posterior third of elytra; in male distinctly surpassing elytral apex. Scape subcylindrical, not reaching anterior margin of pronotum. Antennomere III 1/3 longer than IV; IV slightly shorter than V. Prothorax wider than long in both sexes; sides with lateral tubercle from rounded and slightly distinct to more spiniform and distinct; sides with punctures abundant and confluent. Pronotum with large smooth area centrally; remaining dorsal area coarsely punctate, partially confluent, sides coarsely, densely, confluently punctate. Prosternum coarsely rugose-punctate. Scutellum triangular or with rounded apex. Elytra glabrous, with silky appearance, unicolorous; apex rounded, with minute projection at sutural angle (three females), unarmed in the single male examined. Femora fusiform, with rounded apical projection at inner and outer apices; center of dorsal side of metafemora with long, thick, yellowish setae. Meso- and metatibiae with short spiniform projection at apex. Apex of abdominal ventrite $\mathrm{V}$ rounded in both sexes.

Remarks: According to Martins \& Galileo (2010) (translated): "The presence of the spine at the sides of the prothorax distinguishes luati gen. nov. from all other known genera of Sphallotrichina. By the fusiform metafemora and femora unarmed at apices, it is similar to Butherium Bates, 1870. It differs by the vertex not convex, absence of laterobasal gibbosities on prono- 
tum, pronotal disc with crateriform punctures, scutellum an obtuse triangle, and meso- and metatibiae with short spiniform projection at outer apex. In Butherium, the vertex is notably convex, pronotum (female) has a rounded gibbosity on each side, the pronotal disc is nearly smooth, scutellum has the shape of an equilateral triangle, and the spiniform projection at outer apex is longer."With the description of the first male specimen of luati, we know that the the spiniform lateral tubercle of the prothorax may or may not be present, the shape of the scutellum appears to be very variable, and the vertex (between upper eye lobes and prothorax) is convex as in Butherium. Furthermore, although the center of the pronotum in luati is distinctly punctate, there are specimens of Butherium with sparse punctures on this area. However, there are differences between Butherium and luati, especially in the distance between antennal tubercles, which are distinctly separated in the former (Fig. 16), and more proximate in the latter (Fig. 10). Also, the procoxal cavities in Butherium are closed or nearly so posteriorly (more distinctly open in luati), laterobasal gibbosities on the pronotum of Butherium are much more conspicuous (slightly distinct in luati), protibiae in Butherium are notably and moderately abruptly widened near apex (slightly and gradually widened in luati), and the spiniform projection of the outer apex of meso- and metatibiae is longer in Butherium (shorter in luati). As for the affirmation that luati is the only genus with spiniform tubercles at sides of prothorax in Sphallotrichina, this is not true: Ochrodiongahani (Gounelle, 1909), a species questionably included in this genus, has a very conspicuous spiniform tubercle.

According to Monné (2014): "Paracriodion can be distinguished from luati Martins \& Galileo, 2010 by the unarmed sides of the prothorax and the pronotum with gibbosities and crateriform punctures; in luati, the sides of the prothorax are armed with a prominent median tubercle, and the surface of the pronotum is ornamented with large crateriform punctures, without gibbosities." Actually, Paracriodion Fragoso, 1982 differs from luati only by the antennal tubercles being not nearly contiguous. The crateriform punctures in I. spinithorax are somewhat variable, and do not differ from those in females of $P$. morrisi Monné, 2014, but the pronotal gibbosities, distinct in I. spinithorax, are very slightly conspicuous in I. spinithorax. The general appearance of I. spinithorax, especially females, is much like that of females of $P$. morrisi (including the shape of the area between antennal tubercles and posterior level of upper eye lobes). However, males of the former have antennae distinctly longer, spiniform projection of the tibiae is shorter in both sexes, distance between upper eye lobes is somewhat smaller, and apex of mesoventral process with lateral tabs (according to Monné (2014), absent in Paracriodion).

The presence or absence of the spiniform lateral tubercle in the prothorax has also been observed in another species of Coleoxestia Aurivillius, 1912, genus of Sphallotrichina, described as having an unarmed prothorax, although the presence is rare in that genus (Galileo \& Santos-Silva, 2016).

\section{Iuati spinithorax Martins \& Galileo, 2010 (Figs. 7-13)}

luati spinithorax Martins \& Galileo, 2010: 85; Monné, 2012: 12 (cat.); Monné et al., 2017: 8 (holotype); Monné, 2018: 96 (cat.).

Description: Male (Figs. 7-10): Integument black dorsally; head and prothorax black ventrally; ventral side of meso- and metathorax, and femora dark reddish-brown, lighter toward distal abdominal segments, especially distal area of III and IV, and sides of V; mouthparts dark reddish-brown; antennae gradually dark brown toward distal segments. Elytra opaque.

Head: Frontal plate wide and moderately narrow, not well-delimited, longitudinally sulcate with median groove, sides becoming slightly tumid, and sides of area close to clypeus depressed; with moderately fine, sparse punctures laterally. Frontolateral ridges distinct, elevated; finely, moderately abundantly punctate. Remaining frontal surface finely, moderately sparsely punctate; entire frontal surface glabrous. Area between anterior region of antennal tubercles distinctly, narrowly sulcate; posterior area widely carinate (carina wide up to about middle of upper eye lobes), then distinctly narrow keel-shaped to about level of posterior margin of eyes; depressed, coarsely, confluently, densely punctate on each side of carina (anterior area of carina with sparse, coarse punctures laterally); with a few long, erect golden setae close to upper eye lobes. Remaining surface of vertex convex; coarsely, moderately sparsely punctate toward eyes (punctures distinctly finer than area between upper eye lobes), slightly finer, denser toward prothorax; with minute, sparse yellowish setae laterally. Area behind upper eye lobes coarsely, confluently punctate toward eye, slightly finer and sparser toward prothorax; with short, sparse golden setae, and a few long, erect golden setae close to eye. Area behind lower eye lobes finely, sparsely, shallowly punctate close to eye, transversely sulcate at about middle, nearly smooth toward prothorax; with minute, sparse golden setae close to eye, interspersed with a few long, erect golden setae toward ventral surface, glabrous on remaining surface. Antennal tubercles glabrous; with very fine, sparse punctures basally, smooth on remaining surface. Median groove distinct from clypeus to area between antennal tubercles. Postclypeus nearly perpendicular to frons posteriorly, narrowed centrally on this area, nearly vertical toward anteclypeus; finely sparsely punctate on wide central area close to frons, smooth on remaining surface; glabrous except a few short, erect yellowish setae on sides of area close to anteclypeus. Labrum coplanar with anteclypeus on posterior area (anterior margin of this area distinctly concave), inclined anteriorly; with both, short and long, erect golden setae laterally on posterior area, with long, erect abundant golden setae on inclined area. Genae minutely, sparsely punctate close to eye, smooth toward apex; with short, sparse golden setae toward ventral side. Gulamentum smooth, gla- 

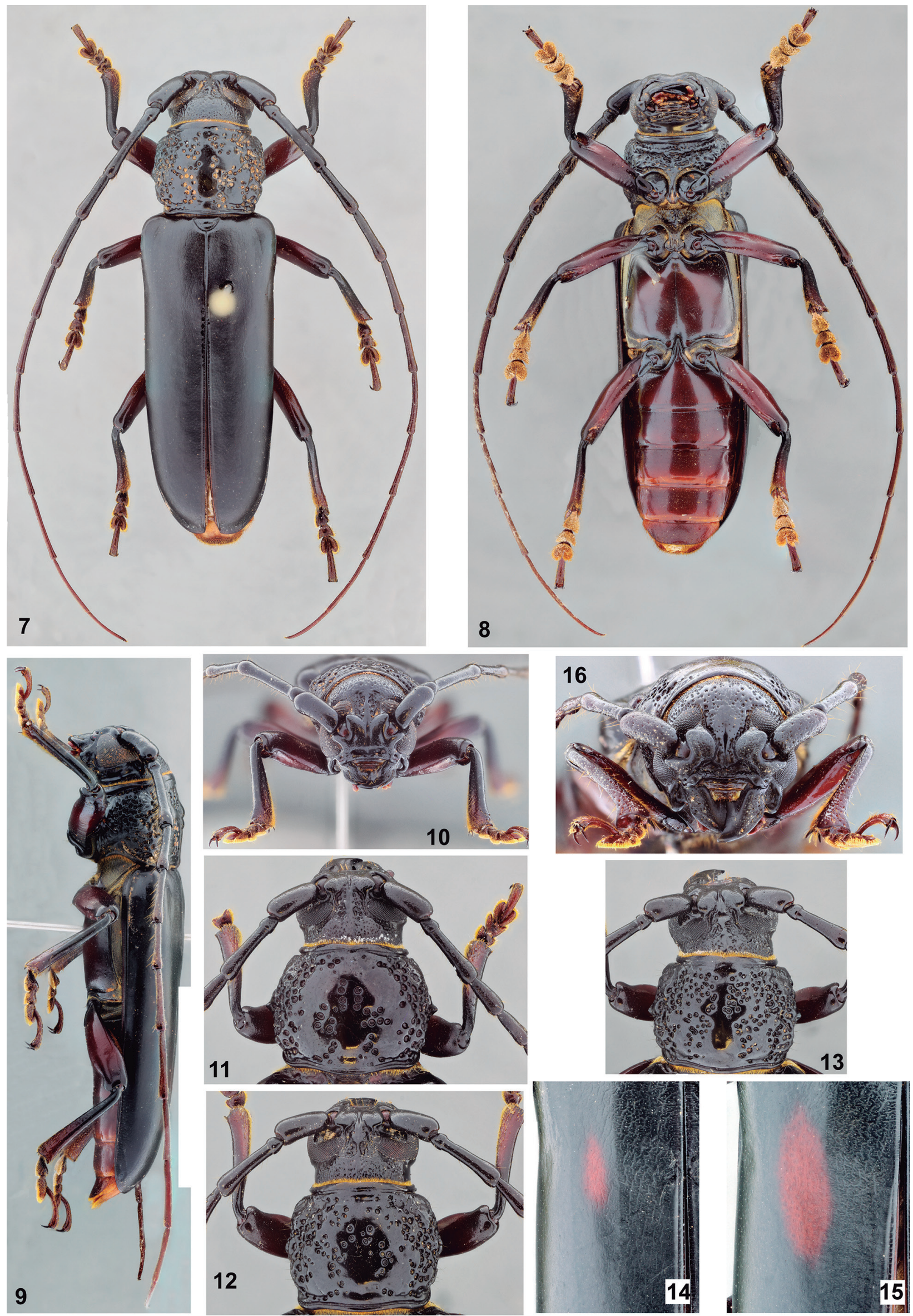

Figures 7-16. (7-15) luati spinithorax: (7) Dorsal habitus, male; (8) Ventral habitus, male; (9) Lateral habitus, male; (10) Head, frontal view, male; (11) Head and prothorax, holotype female; (12) Head and prothorax, female 1; (13) Head and prothorax, female 2; (14) Elytron, female 1; (15) Elytron, female 2. (16) Butherium erythropus, head, frontal view, female. 
brous close to prothorax, slightly depressed, transversely rugose, with both short and long, erect, sparse yellowish setae between lower eye lobes. Distance between upper eye lobes 0.55 times length of scape; in frontal view, distance between lower eye lobes nearly equal to length of scape. Antennae 2.1 times elytral length, reaching elytral apex about middle of antennomere IX. Scape finely, sparsely punctate; with moderately short, sparse golden setae ventrally, glabrous on remaining surface. Antennomere III with elongate sensorial area on inner side of distal quarter; finely, sparsely punctate (punctures slightly denser than on scape); with long, erect golden setae ventrally, a few long, erect setae of same color dorsally near apex, and sparse golden pubescence laterally on distal third. Antennomere IV with sculpturing and erect setae as on III, but golden pubescence more abundant including dorsally; inner side with short sensorial area on basal third, and long sensorial area on distal half. Antennomeres V-X with ventral erect setae sparser, gradually sparser toward X (present only posteriorly after VII); dorsal erect setae as on III; with golden pubescence throughout, denser than on IV; inner side of IV with sensorial area from near base to near apex. Antennomere $\mathrm{XI}$ nearly divided after middle; with golden pubescence throughout. Antennal formula (ratio) based on length of antennomere III: scape $=0.64$; pedicel $=0.16$; IV $=0.68$; $\mathrm{V}=0.75 ; \mathrm{VI}=0.78 ; \mathrm{VII}=0.79 ; \mathrm{VIII}=0.80 ; \mathrm{IX}=0.85 ; \mathrm{X}=0.89$; $\mathrm{XI}=1.52$.

Thorax: Prothorax 1.3 times wider than long; anteriorly and posteriorly abruptly constricted, anterior constriction narrower than posterior constriction; with narrow transverse sulcus surrounding area adjacent to anterior constriction. Pronotum coarsely, moderately sparsely punctate except smooth central area, areas of lateral gibbosities, and narrow anterior area, denser, confluent laterally (becoming strongly rugose); with a few long, erect yellowish-brown setae on sides of posterior third. Sides of prothorax unarmed; coarsely, densely rugose-punctate except smooth narrow area close to anterior margin; with a few long, erect yellowish-brown setae. Prosternum coarsely, confluently rugose-punctate on posterior half; with transverse sulcus about middle, and another transverse sulcus close to anterior constriction (following that on pronotum); nearly smooth close to anterior margin; with moderately narrow sulcus close to anterior margin of procoxal cavities, following toward anterior half of sides of prosternal process; with yellowish pubescence inside sulcus close to procoxal cavities, and both, short and long, very sparse yellowish-brown setae on rugose-punctate area. Prosternal process carinate centrally at basal quarter, then sulcate toward posterior third; with tab on each side of area after middle of procoxae, gradually widened from this point to apex; with sparse yellowish pubescence on basal 2/3, distinctly denser on distal third. Mesoventrite with golden pubescence not obscuring integument centrally, denser laterally except nearly glabrous apex. Mesanepisternum, mesepimeron, and metanepisternum with golden pubescence partially obscuring integument. Mesoventral process emarginate at center of posterior margin, with distinct tab on each side of posterior area. Metaventrite glabrous except golden pubescence laterally close to metacoxal cavities. Scutellum wider than high, rounded apically, nearly smooth, with minute, slightly distinct yellowish setae close to margins. Elytra: Minutely punctate, with each puncture surrounded by surface finely reticulate(reticule gradually less distinct toward apex); surface glabrous. Legs: Femora minutely, sparsely punctate on basal 3/4, slightly densely on distal quarter; with minute almost indistinct setae posteriorly; metafemora with fringe of short, golden setae about middle of dorsal surface. Tibiae gradually widened from base to apex; with abundant, erect golden setae on ventral surface of distal half, sparser on sides of posterior quarter.

Abdomen: Ventrites finely, sparsely punctate (punctures slightly coarser and denser toward V); glabrous except minute yellowish setae laterally ( $V$ with some long, erect yellowish-brown setae near center of apex); ventrite $\mathrm{V}$ slightly depressed on narrow area close to center of distal area, and distal margin rounded.

Dimensions ( $\mathbf{m m})$, one male/3 females: Total length, 34.00/35.70-37.30; prothoracic length, 6.45/6.55-6.65; anterior prothoracic width, 6.00/5.75-6.20; posterior prothoracic width, 6.40/6.90-7.25; maximum prothoracic width, 8.25/8.90-9.15; humeral width, 9.45/10.55-10.90; elytral length, 22.70/24.45-26.00.

Material examined: PERU Loreto: Pucacuro (Rio Corrientes; -3.447567/-75.429325), 1 male, 11.VIII.2012, J.J.R. Hernandez col. (MZSP); 1 female, 30.V.2011, J.J.R. Hernandez col. (JJRH); 1 female, 12.VIII.2012, J.J.R. Hernandez col. (JJRH). (New country record), BRAZIL, Rondônia: Porto Velho (Parque Ecológico), holotype female, 09.XI.2008, no collector indicated (MZSP).

Remarks: Variation in elytral color was observed in the four specimens examined: in the male and holotype female, the elytra are entirely black, while in the two other females there is a distinct elliptical red macula on the center of the dorsal surface of the anterior half, small in one female (Fig. 14), larger in another (Fig. 15).

\section{ACKNOWLEDGMENTS}

We express our thanks to Larry Bezark for sending the photograph of the holotype of Criodion plagiatum. The first author is grateful for the grant 2017/15283-9, São Paulo Research Foundation (FAPESP).

\section{REFERENCES}

Galileo, M.H.M. \& Santos-Silva, A. 2016. New taxa, new records and notes on Coleoxestia Aurivillius, 1912 (Coleoptera, Cerambycidae, Cerambycinae). Zootaxa, 4136(1): 54-70. 
Martins, U.R. \& Galileo, M.H.M. 2010. Novas espécies, nova sinonímia e novo registro em Cerambycidae (Coleoptera) do México e da América do Sul. Papéis Avulsos de Zoologia, 50(7): 83-90.

Martins, U.R. \& Monné, M.A. 2005. Tribo Cerambycini, Subtribo Sphallotrichina, In: Martins, U.R. (Org.). Cerambycidae Sul-Americanos (Coleoptera), Taxonomia. São Paulo, Sociedade Brasileira de Entomologia. v. 5, p. 1-218.

Monné, M.A. 2012. Catalogue of the type-species of the genera of the Cerambycidae, Disteniidae, Oxypeltidae and Vesperidae (Coleoptera) of the Neotropical Region. Zootaxa, 3213: 1-183.
Monné, M.A. 2014. Paracriodion Fragoso (Coleoptera, Cerambycidae, (erambycinae); redefinition, with description of a new species from Bolivia. Zootaxa, 3847(1): 139-144.

Monné, M.A. 2018. Catalogue of the Cerambycidae (Coleoptera) of the Neotropical region. Part I. Subfamily Cerambycinae. Available at: http:// cerambyxcat.com. Access in: 07/2018.

Monné, M.A.; Santos-Silva, A.; Casari, S.A. \& Monné, M.L. 2017. Checklist of Cerambycidae, Disteniidae and Vesperidae (Coleoptera) primary types of the Museu de Zoologia, Universidade de São Paulo, São Paulo, Brazil. Zootaxa, 4249(1): 1-104. 